IVAN ILLICH

Medical nemesis*

Ivan Illich

J Epidemiol Community Health 2003;57:919-922

This article was originally published in the Lancet in 1974. $\dagger$ It is reprinted here, as the centre of a set of articles, in memory of the death of Ivan Illich in December 2002.

W ithin the last decade medical professional practice has become a major threat to health. Depression, infection, disability, dysfunction, and other specific iatrogenic diseases now cause more suffering than all accidents from traffic or industry. Beyond this, medical practice sponsors sickness by the reinforcement of a morbid society which not only industrially preserves its defectives but breeds the therapist's client in a cybernetic way. Finally, the so-called health-professions have an indirect sickening power-a structurally health-denying effect. I want to focus on this last syndrome, which I designate as medical Nemesis. By transforming pain, illness, and death from a personal challenge into a technical problem, medical practice expropriates the potential of people to deal with their human condition in an autonomous way and becomes the source of a new kind of un-health.

Much suffering has always been man-made: history is the record of enslavement and exploitation. It tells of war, and of the pillage, famine, and pestilence which come in its wake. War between commonwealths and classes has so far been the main planned agency of man-made misery. Thus, man is the only animal whose evolution has been conditioned by adaptation on two fronts. If he did not succumb to the elements, he had to cope with use and abuse by others of his kind. He replaced instincts by character and culture, to be capable of this struggle on two frontiers. A third frontier of possible doom has been recognised since Homer; but common mortals were considered immune to its threat. Nemesis, the Greek name for the awe which loomed from this third direction, was the fate of a few heroes who had fallen prey to the envy of the gods. The common man grew up and perished in a struggle with Nature and neighbour. Only the élite would challenge the thresholds set by Nature for man.

Prometheus was not Everyman, but a deviant. Driven by Pleonexia, or radical greed, he tres-

*Abridged from a lecture given in Edinburgh on April 26 and in Nottingham on May 1, 1974. The lecture is based on the book Medical Nemesis, which is to be published this autumn by Calder and Boyars.

†This article is reprinted with permission from Elsevier (Lancet 1974;i:918-21). (http://www.elsevier.com/ locate/lancet) passed the boundaries of the human condition. In hubris or measureless presumption, he brought fire from heaven, and thereby brought Nemesis on himself. He was put into irons on a Caucasian rock. A vulture preys at his innards, and heartlessly healing gods keep him alive by regrafting his liver each night. The encounter with Nemesis made the classical hero an immortal reminder of inescapable cosmic retaliation. He becomes a subject for epic tragedy, but certainly not a model for everyday aspiration. Now Nemesis has become endemic; it is the backlash of progress. Paradoxically, it has spread as far and as wide as the franchise, schooling, mechanical acceleration, and medical care. Everyman has fallen prey to the envy of the gods. If the species is to survive it can do so only by learning to cope in this third group.

\section{INDUSTRIAL NEMESIS}

Most man-made misery is now the byproduct of enterprises which were originally designed to protect the common man in his struggle with the inclemency of the environment and against wanton injustices inflicted by the elite. The main source of pain, disability, and death is now an engineered-albeit non-intentional-harassment. The prevailing ailments, helplessness and injustice, are now the side-effects of strategies for progress. Nemesis is now so prevalent that it is readily mistaken for part of the human condition. The desperate disability of contemporary man to envisage an alternative to the industrial aggression on the human condition is an integral part of the curse from which he suffers. Progress has come with a vengeance which cannot be called a price. The down payment was on the label and can be stated in measurable terms. The instalments accrue under forms of suffering which exceed the notion of "pain".

At some point in the expansion of our major institutions their clients begin to pay a higher price every day for their continued consumption, in spite of the evidence that they will inevitably suffer more. At this point in development the prevalent behaviour of society corresponds to that traditionally recognised in addicts. Declining returns pale in comparison with marginally increasing disutilities. Homo economicus turns into Homo religiosus. His expectations become heroic. The vengeance of economic development not only outweighs the price at which this vengeance was purchased; it also outweighs the compound tort done by Nature and neighbours. Classical Nemesis was punishment for the rash abuse of a privilege. Industrialised Nemesis is retribution for dutiful participation in society. 
War and hunger, pestilence and sudden death, torture and madness remain man's companions, but they are now shaped into a new Gestalt by the Nemesis overarching them. The greater the economic progress of any community, the greater the part played by industrial Nemesis in the pain, discrimination, and death suffered by its members. Therefore, it seems that the disciplined study of the distinctive character of Nemesis ought to be the key theme for research amongst those who are concerned with health care, healing, and consoling.

\section{TANTALUS}

Medical Nemesis is but one aspect of the more general "counter-intuitive misadventures" characteristic of industrial society. It is the monstrous outcome of a very specific dream of reason-namely, "tantalising" hubris. Tantalus was a famous king whom the gods invited to Olympus to share one of their meals. He purloined Ambrosia, the divine potion which gave the gods unending life. For punishment, he was made immortal in Hades and condemned to suffer unending thirst and hunger. When he bows towards the river in which he stands, the water recedes, and when he reaches for the fruit above his head the branches move out of his reach. Ethologists might say that Hygienic Nemesis has programmed him for compulsory counter-intuitive behaviour. Craving for Ambrosia has now spread to the common mortal. Scientific and political optimism have combined to propagate the addiction. To sustain it, the priesthood of Tantalus has organised itself, offering unlimited medical improvement of human health. The members of this guild pass themselves off as disciples of healing Asklepios, while in fact they peddle Ambrosia. People demand of them that life be improved, prolonged, rendered compatible with machines, and capable of surviving all modes of acceleration, distortion, and stress. As a result, health has become scarce to the degree to which the common man makes health depend upon the consumption of Ambrosia.

\section{CULTURE AND HEALTH}

Mankind evolved only because each of its individuals came into existence protected by various visible and invisible cocoons. Each one knew the womb from which he had come, and oriented himself by the stars under which he was born. To be human and to become human, the individual of our species has to find his destiny in his unique struggle with Nature and neighbour. He is on his own in the struggle, but the weapons and the rules and the style are given to him by the culture in which he grew up. Each culture is the sum of rules with which the individual could come to terms with pain, sickness, and death-could interpret them and practise compassion amongst others faced by the same threats. Each culture set the myth, the rituals, the taboos, and the ethical standards needed to deal with the fragility of life-to explain the reason for pain, the dignity of the sick, and the role of dying or death.

Cosmopolitan medical civilisation denies the need for man's acceptance of these evils. Medical civilisation is planned and organised to kill pain, to eliminate sickness, and to struggle against death. These are new goals, which have never before been guidelines for social life and which are antithetic to every one of the cultures with which medical civilisation meets when it is dumped on the so-called poor as part and parcel of their economic progress.

The health-denying effect of medical civilisation is thus equally powerful in rich and in poor countries, even though the latter are often spared some of its more sinister sides.

\section{THE KILLING OF PAIN}

For an experience to be pain in the full sense, it must fit into a culture. Precisely because each culture provides a mode for suffering, culture is a particular form of health. The act of suffering is shaped by culture into a question which can be stated and shared.

Medical civilisation replaces the culturally determined competence in suffering with a growing demand by each individual for the institutional management of his pain. A myriad of different feelings, each expressing some kind of fortitude, are homogenised into the political pressure of anaesthesia consumers. Pain becomes an item on a list of complaints. As a result, a new kind of horror emerges. Conceptually it is still pain, but the impact on our emotions of this valueless, opaque, and impersonal hurt is something quite new.

In this way, pain has come to pose only a technical question for industrial man-what do I need to get in order to have my pain managed or killed? If the pain continues, the fault is not with the universe, God, my sins, or the devil, but with the medical system. Suffering is an expression of consumer demand for increased medical outputs. By becoming unnecessary, pain has become unbearable. With this attitude, it now seems rational to flee pain rather than to face it, even at the cost of addiction. It also seems reasonable to eliminate pain, even at the cost of health. It seems enlightened to deny legitimacy to all non-technical issues which pain raises, even at the cost of disarming the victims of residual pain. For a while it can be argued that the total pain anaesthetised in a society is greater than the totality of pain newly generated. But at some point, rising marginal disutilities set in. The new suffering is not only unmanageable, but it has lost its referential character. It has become meaningless, questionless torture. Only the recovery of the will and ability to suffer can restore health into pain.

\section{THE ELIMINATION OF SICKNESS}

Medical interventions have not affected total mortality-rates: at best they have shifted survival from one segment of the population to another. Dramatic changes in the nature of disease afflicting Western societies during the last 100 years are well documented. First industrialisation exacerbated infections, which then subsided. Tuberculosis peaked over a 50-75-year period and declined before either the tubercle bacillus had been discovered or anti-tuberculous programmes had been initiated. It was replaced in Britain and the U.S. by major malnutrition syndromes-rickets and pellagra-which peaked and declined, to be replaced by disease of early childhood, which in turn gave way to duodenal ulcers in young men. When that declined the modern epidemics took their toll-coronary heart-disease, hypertension, cancer, arthritis, diabetes, and mental disorders. At least in the U.S., death-rates from hypertensive heart-disease seem to be declining. Despite intensive research no connection between these changes in disease patterns can be attributed to the professional practice of medicine.

Neither decline in any of the major epidemics of killing diseases, nor major changes in the age structure of the population, nor falling and rising absenteeism at the workbench have been significantly related to sick care-even to immunisation. Medical services deserve neither credit for longevity nor blame for the threatening population pressure.

Longevity owes much more to the railroad and to the synthesis of fertilisers and insecticides than it owes to new drugs and syringes. Professional practice is both ineffective and increasingly sought out. This technically unwarranted rise of medical prestige can only be explained as a magical ritual for the achievement of goals which are beyond technical and political reach. It can be countered only 
through legislation and political action which favours the deprofessionalisation of health care.

The overwhelming majority of modern diagnostic and therapeutic interventions which demonstrably do more good than harm have two characteristics: the material resources for them are extremely cheap, and they can be packaged and designed for self-use or application by family members. The price of technology that is significantly health-furthering or curative in Canadian medicine is so low that the resources now squandered in India on modern medicine would suffice to make it available in the entire sub-continent. On the other hand, the skills needed for the application of the most generally used diagnostic and therapeutic aids are so simple that the careful observation of instruction by people who personally care would guarantee more effective and responsible use than medical practice can provide.

The deprofessionalisation of medicine does not imply and should not be read as implying negation of specialised healers, of competence, of mutual criticism, or of public control. It does imply a bias against mystification, against transnational dominance of one orthodox view, against disbarment of healers chosen by their patients but not certified by the guild. The deprofessionalisation of medicine does not mean denial of public funds for curative purposes, it does mean a bias against the disbursement of any such funds under the prescription and control of guild-members, rather than under the control of the consumer. Deprofessionalisation does not mean the elimination of modern medicine, nor obstacles to the invention of new ones, nor necessarily the return to ancient programmes, rituals, and devices. It means that no professional shall have the power to lavish on any one of his patients a package of curative resources larger than that which any other could claim on his own. Finally, the deprofessionalisation of medicine does not mean disregard for the special needs which people manifest at special moments of their lives; when they are born, break a leg, marry, give birth, become crippled, or face death. It only means that people have a right to live in an environment which is hospitable to them at such high points of experience.

\section{THE STRUGGLE AGAINST DEATH}

The ultimate effect of medical Nemesis is the expropriation of death. In every society the image of death is the culturally conditioned anticipation of an uncertain date. This anticipation determines a series of behavioural norms during life and the structure of certain institutions.

Wherever modern medical civilisation has penetrated a traditional medical culture, a novel cultural ideal of death has been fostered. The new ideal spreads by means of technology and the professional ethos which corresponds to it.

In primitive societies death is always conceived as the intervention of an actor-an enemy, a witch, an ancestor, or a god. The Christian and the Islamic Middle Ages saw in each death the hand of God. Western death had no face until about 1420. The Western ideal of death which comes to all equally from natural causes is of quite recent origin. Only during the autumn of the Middle Ages death appears as a skeleton with power in its own right. Only during the 16th century, as an answer European peoples developed the "arte and crafte to knowe ye Will to Dye". For the next three centuries peasant and noble, priest and whore, prepared themselves throughout life to preside at their own death. Foul death, bitter death, became the end rather than the goal of living. The idea that natural death should come only in healthy old age appeared only in the 18th century as a classspecific phenomenon of the bourgeois. The demand that doctors struggle against death and keep valetudinarians healthy has nothing to do with their ability to provide such service: Ariès has shown that the costly attempts to prolong life appear at first only among bankers whose power is compounded by the years they spend at a desk.

We cannot fully understand contemporary social organisation unless we see in it a multi-faceted exorcism of all forms of evil death. Our major institutions constitute a gigantic defence programme waged on behalf of "humanity" against all those people who can be associated with what is currently conceived of as death-dealing social injustice. Not only medical agencies, but welfare, international relief, and development programmes are enlisted in this struggle. Ideological bureaucracies of all colours join the crusade. Even war has been used to justify the defeat of those who are blamed for wanton tolerance of sickness and death. Producing "natural death" for all men is at the point of becoming an ultimate justification for social control. Under the influence of medical rituals contemporary death is again the rationale for a witch-hunt.

\section{CONCLUSION}

Rising irreparable damage accompanies industrial expansion in all sectors. In medicine these damages appear as iatrogenesis. Iatrogenesis can be direct, when pain, sickness, and death result from medical care; or it can be indirect, when health policies reinforce an industrial Organisation which generates ill-health: it can be structural when medically sponsored behaviour and delusion restrict the vital autonomy of people by undermining their competence in growing up, caring, ageing; or when it nullifies the personal challenge arising from their pain, disability, and anguish.

Most of the remedies proposed to reduce iatrogenesis are engineering interventions. They are therapeutically designed in their approach to the individual, the group, the institution, or the environment. These so-called remedies generate second-order iatrogenic ills by creating a new prejudice against the autonomy of the citizen.

The most profound iatrogenic effects of the medical technostructure result from its non-technical social functions. The sickening technical and non-technical consequences of the institutionalisation of medicine coalesce to generate a new kind of suffering - anaesthetised and solitary survival in a world-wide hospital ward.

Medical Nemesis cannot be operationally verified. Much less can it be measured. The intensity with which it is experienced depends on the independence, vitality, and relatedness of each individual. As a theoretical concept it is one component in a broad theory to explain the anomalies plaguing health-care systems in our day. It is a district aspect of an even more general phenomenon which I have called industrial Nemesis, the backlash of institutionally structured industrial hubris. This hubris consists of a disregard for the boundaries within which the human phenomenon remains viable. Current research is overwhelmingly oriented towards unattainable "breakthroughs". What I have called counterfoil research is the disciplined analysis of the levels at which such reverberations must inevitably damage man.

The perception of enveloping Nemesis leads to a social choice. Either the natural boundaries of human endeavour are estimated, recognised, and translated into politically determined limits, or the alternative to extinction is compulsory survival in a planned and engineered Hell.

In several nations the public is ready for a review of its health-care system. The frustrations which have become manifest from private-enterprise systems and from socialised care have come to resemble each other frighteningly. The differences between the annoyances of the Russian, French, Americans, and English have become trivial. There is a serious danger that these evaluations will be performed within the coordinates set by post-cartesian illusions. In rich 
and poor countries the demand for reform of national health care is dominated by demands for equitable access to the wares of the guild, professional expansion and sub-professionalisation, and for more truth in the advertising of progress and lay-control of the temple of Tantalus. The public discussion of the health crisis could easily be used to channel even more power, prestige, and money to biomedical engineers and designers.

There is still time in the next few years to avoid a debate which would reinforce a frustrating system. The coming debate can be reoriented by making medical Nemesis the central issue. The explanation of Nemesis requires simultaneous assessment of both the technical and the non-technical side of medicine-and must focus on it as both industry and religion. The indictment of medicine as a form of institutional hubris exposes precisely those personal illusions which make the critic dependent on the health care.

The perception and comprehension of Nemesis has therefore the power of leading us to policies which could break the magic circle of complaints which now reinforce the dependence of the plaintiff on the health engineering and planning agencies whom he sues. Recognition of Nemesis can provide the catharsis to prepare for a non-violent revolution in our attitudes towards evil and pain. The alternative to a war against these ills is the search for the peace of the strong.

Health designates a process of adaptation. It is not the result of instinct, but of autonomous and live reaction to an experienced reality. It designates the ability to adapt to changing environments, to growing up and to ageing, to healing when damaged, to suffering and to the peaceful expectation of death. Health embraces the future as well, and therefore includes anguish and the inner resource to live with it.

Man's consciously lived fragility, individuality, and relatedness make the experience of pain, of sickness, and of death an integral part of his life. The ability to cope with this trio in autonomy is fundamental to his health. To the degree to which he becomes dependent on the management of his intimacy he renounces his autonomy and his health must decline. The true miracle of modern medicine is diabolical. It consists of making not only individuals but whole populations survive on inhumanly low levels of personal health. That health should decline with increasing health-service delivery is unforeseen only by the health manager, precisely because his strategies are the result of his blindness to the inalienability of health.

The level of public health corresponds to the degree to which the means and responsibility for coping with illness are distributed amongst the total population. This ability to cope can be enhanced but never replaced by medical intervention in the lives of people or the hygienic characteristics of the environment. That society which can reduce professional intervention to the minimum will provide the best conditions for health. The greater the potential for autonomous adaptation to self and to others and to the environment, the less management of adaptation will be needed or tolerated.

The recovery of a health attitude towards sickness is neither Luddite nor Romantic nor Utopian: it is a guiding ideal which will never be fully achieved, which can be achieved with modern devices as never before in history, and which must orient politics to avoid encroaching Nemesis.

A review of modern alternatives to medical professionalism is in progress at the Center for International Documentation, APDO 479, Cuernavaca, Mexico. For information, write to Valentina Borremans.

\section{Author's affiliations}

Ivan Illich, Cuernavaca, Mexico 